\title{
Effects of Pantethine on Action Potential of Canine Papillary Muscle during Hypoxic Perfusion
}

\author{
Hideharu Hayashi, M.D., Akira Kobayashi, M.D., \\ Hajime Terada, M.D., Bunnosuke Nagao, M.D., \\ Terumasa Nishiyama, M.D., Tadashi Kamikawa, M.D., \\ and Noboru Yamazaki, M.D.
}

\section{Summary}

Pantethine, which is known to be converted to coenzyme $A$, has been reported to have antiarrhythmic action on experimental cardiac arrhythmias. Using standard microelectrode techniques, the electrophysiological effects of pantethine under hypoxic (95\% $\mathrm{N}_{2}+5 \% \mathrm{CO}_{2}$ ) perfusion were studied.

Hypoxia decreased resting membrane potential, action potential amplitude and maximum velocity of phase 0 and shortened action potential duration and effective refractory period. Application of pantethine $5 \times 10^{-3} \mathrm{Gm} / \mathrm{ml}$ under hypoxic perfusion prolonged action potential duration and effective refractory period significantly. Prolongation of action potential duration by pantethine might be caused by an increase in intracellular ATP.

The findings in this study could be an explanation of the possible antiarrhythmic effects of pantethine.

\section{Additional Indexing Words:}

Electrophysiology Antiarrhythmic action Coenzyme A ATP

$7 \mathrm{HE}$ earliest and most striking effect of hypoxia on cardiac muscle is shortening of action potential duration. ${ }^{1,2)}$ The effect has been attributed to a decrease in glycolytically derived ATP in the cytoplasm. ${ }^{31,4)}$

Pantethine, a coenzyme A (CoA) precursor, has been reported to have antiarrhythmic action on experimental cardiac arrhythmias, ${ }^{5)}$ including ouabain-induced arrhythmias in guinea-pigs, $\mathrm{CaCl}_{2}$-induced and aconitine-induced arrhythmias in rats and halothane + epinephrine-induced arrhythmias

From the Third Department of Internal Medicine, Hamamatsu University School of Medicine, Hamamatsu, Japan.

Address for reprint: Hideharu Hayashi, M.D., Third Department of Internal Medicine, Hamamatsu University School of Medicine, 3600 Handa-cho, Hamamatsu 431-31, Japan.

Received for publication March 16, 1984.

Manuscript revised June 7, 1984. 
in dogs. As pantethine is reported to be converted to CoA in the liver, ${ }^{61,7)}$ it is possible that pantethine may modify both carbohydrate and lipid metabolism and thereby influence myocardial energy production.

The purpose of this study was to observe the electrophysiological effects of pantethine on transmembrane action potentials under hypoxic perfusion.

\section{Materials and Methods}

Mongrel dogs weighing $8-12 \mathrm{Kg}$ were anesthetized with sodium pentobarbital $(30 \mathrm{mg} / \mathrm{Kg}$, iv). The hearts were removed and immediately placed in cooled and oxygenated Tyrode's solution. A small sample of papillary muscle was rapidly excised from the right ventricle and placed in a tissue bath. The bath was perfused with $95 \% \mathrm{O}_{2}$ and $5 \% \mathrm{CO}_{2}$ at a constant rate of $7 \mathrm{ml} /$ min. Temperature was maintained at $36 \pm 0.5^{\circ} \mathrm{C}$. The $\mathrm{pH}$ of the solution was maintained at 7.4. The composition of the solution was as follows in $\mathrm{mM}$ : $\mathrm{NaCl}, 137 ; \mathrm{NaHCO}_{3}, 12$; dextrose, $5.5 ; \mathrm{KCl}, 3.0 ; \mathrm{CaCl}_{2}, 2.7 ; \mathrm{NaH}_{2}-$ $\mathrm{PO}_{4}, 1.8$; and $\mathrm{MgCl}_{2}, 0.5$. The papillary muscle was stimulated at a basic cycle length of $1,000 \mathrm{msec}$ with rectangular pulses of $2.0 \mathrm{msec}$ duration and twice the diastolic threshold in intensity through a bipolar Teflon-coated silver electrode placed on the papillary muscle at one end of the preparation.

Transmembrane action potentials were recorded from papillary muscle by means of a machine-pulled glass microelectrode filled with $3 \mathrm{M} \mathrm{KCl}$ and with tip resistances of 10 to 15 megohms. The following parameters were measured: resting membrane potential (RMP), action potential amplitude (APA) and duration of action potential from the upstroke to 20,50 and $90 \%$ repolarization $\left(\mathrm{APD}_{20}, \mathrm{APD}_{50}, \mathrm{APD}_{90}\right)$. The effective refractory period (ERP) was measured while the preparation was stimulated at a basic cycle length of 1,000 msec. Premature stimuli were introduced during every eighth cycle. Premature stimuli were initially placed during the absolute refractory period and were then gradually and progressively delayed until the first impulse that propagated to a microelectrode was obtained. The maximum upstroke velocity of phase $0\left(\mathrm{dV} / \mathrm{dt}_{\max }\right)$ was obtained by electronic differentiation and displayed on an oscilloscope.

After the preparation was superfused for at least 30 min under normal perfusing conditions (saturated with $95 \% \mathrm{O}_{2}+5 \% \mathrm{CO}_{2}, \mathrm{pO}_{2} 600-650 \mathrm{mmHg}$, $\mathrm{pH} 7.4$ ), the perfusing condition was switched to either (1) hypoxic perfusion for $60 \mathrm{~min}$ (saturated with 95\% $\mathrm{N}_{2}+5 \% \mathrm{CO}_{2}, \mathrm{pO}_{2} 60-65 \mathrm{mmHg}, \mathrm{pH} \mathrm{7.4)} \mathrm{or}$ (2) hypoxic perfusion for $30 \mathrm{~min}$ and then hypoxic perfusion containing pantethine $5 \times 10^{-3} \mathrm{Gm} / \mathrm{ml}$ for $30 \mathrm{~min}$.

Values are expressed as mean $\pm \mathrm{SD}$. Statistical analysis was performed 
using non-paired Student's t-test and the significance was established at $\mathrm{p}<$ 0.05 .

\section{Results}

\section{(1) Effects of hypoxic perfusion}

The sequential changes in various parameters of transmembrane action potentials under hypoxic perfusion are summarized in Fig. 1. RMP was decreased from $-81 \pm 2.0$ to $-78 \pm 2.1 \mathrm{mV}$ after $30 \mathrm{~min}$ and to $-77 \pm 3.2$ $\mathrm{mV}$ after $60 \mathrm{~min}$. APA was decreased from $100 \pm 3.5$ to $96 \pm 5.2 \mathrm{mV}$ after $30 \mathrm{~min}$ and to $92 \pm 5.2 \mathrm{mV}$ after $60 \mathrm{~min}$. $\mathrm{dV} / \mathrm{dt}_{\max }$ was also decreased from
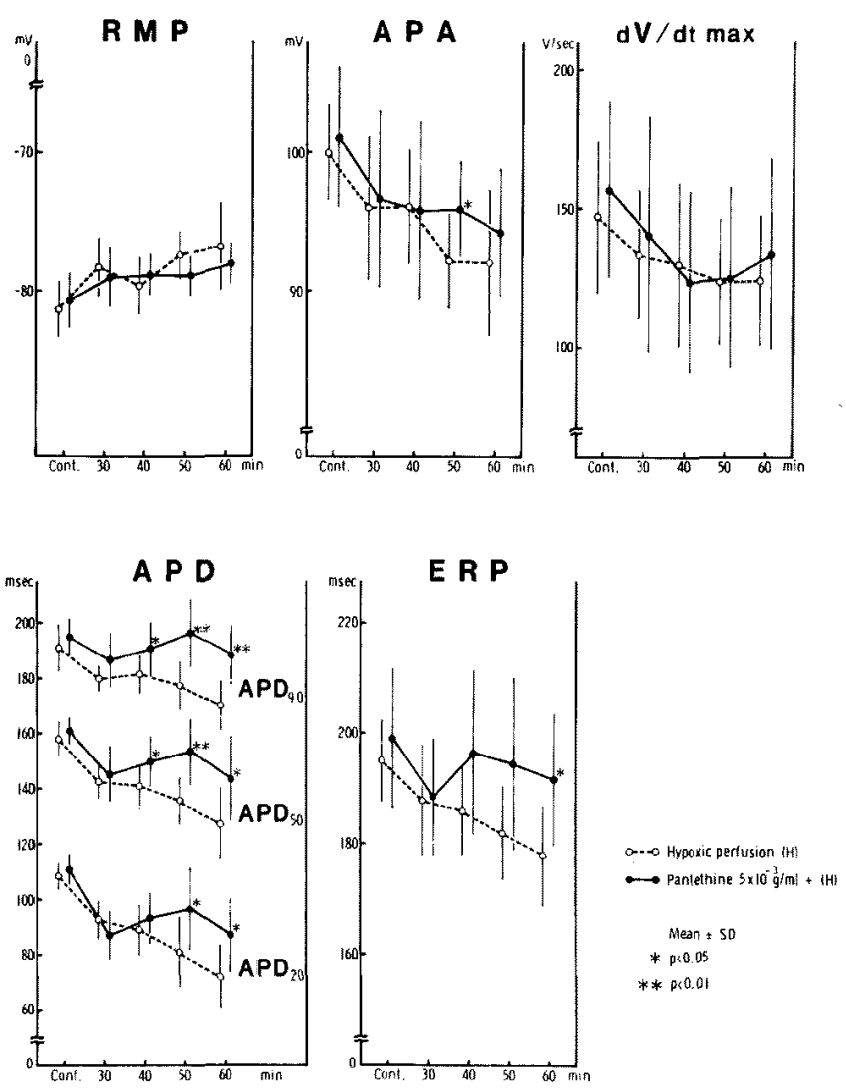

Fig. 1. Sequential changes in various parameters of the transmembrane action potentials of canine papillary muscle produced by hypoxic perfusion and application of pantethine $5 \times 10^{-8} \mathrm{Gm} / \mathrm{ml}$ under hypoxic perfusion. Abbreviations: $\quad \mathrm{RMP}=$ resting membrane potential; $\mathrm{APA}=$ action potential amplitude; $\mathrm{dV} / \mathrm{dt}_{\max }=$ maximum upstroke velocity of phase $0 ; A P D=$ action potential duration; $\mathbf{E R P}=$ effective refractory period. Asterisks indicate the significant differences by a non-paired t-test. 


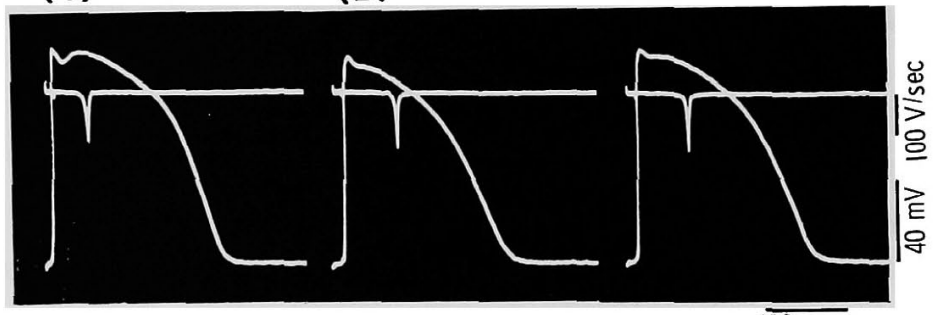

$\overline{100 \mathrm{msec}}$

Fig. 2. Effects of hypoxic perfusion on action potential. (1) control (2) $30 \mathrm{~min}$ after exposure to hypoxia (3) $50 \mathrm{~min}$ after exposure to hypoxia.

(1)

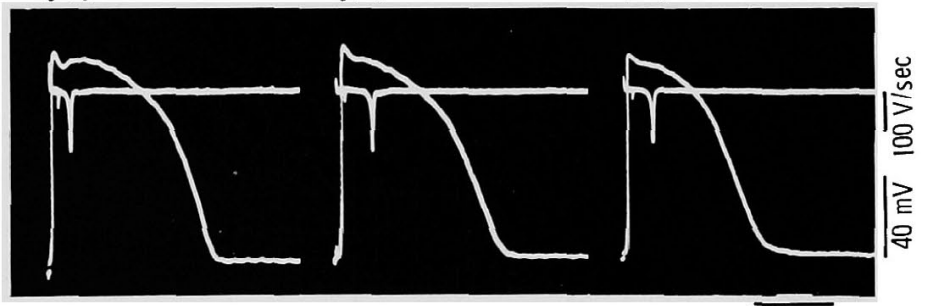

$1 \overline{00 \mathrm{msec}}$

Fig. 3. Effects of pantethine $5 \times 10^{-3} \mathrm{Gm} / \mathrm{ml}$ on hypoxia-induced changes in action potential. (1) control (2) $30 \mathrm{~min}$ after exposure to hypoxia (before drug application) (3) $20 \mathrm{~min}$ after application of pantethine $5 \times 10^{-3} \mathrm{Gm} / \mathrm{ml}$ under hypoxia (50 min after exposure to hypoxia).

$147 \pm 27.4$ to $133 \pm 23.2 \mathrm{~V} / \mathrm{sec}$ after $30 \mathrm{~min}$ and to $124 \pm 23.8 \mathrm{~V} / \mathrm{sec}$ after 60 min. $\mathrm{APD}_{20}$ was shortened from $109 \pm 4.9$ to $93 \pm 7.1,89 \pm 9.0,81 \pm 12.8$ and $72 \pm 11.9 \mathrm{msec}$ after $30,40,50$ and $60 \mathrm{~min}$, respectively. $\mathrm{APD}_{50}$ was shortened from $158 \pm 6.3$ to $143 \pm 6.2,141 \pm 7.2,136 \pm 8.8$ and $127 \pm 13.1 \mathrm{msec}$ after $30,40,50$ and $60 \mathrm{~min}$. $\mathrm{APD}_{90}$ was also shortened from $191 \pm 8.8$ to $180 \pm 4.9,181 \pm 6.9,177 \pm 8.8$ and $170 \pm 9.1 \mathrm{msec}$ after $30,40,50$ and 60 min. ERP, which had a control value of $195 \pm 7.6 \mathrm{msec}$, was progressively shortened to $188 \pm 10.0,186 \pm 8.0,182 \pm 8.4$ and $178 \pm 9.0 \mathrm{msec}$ after 30,40 , 50 and $60 \mathrm{~min}$, respectively.

Action potentials in a representative case are shown in Fig. 2.

\section{(2) Effects of pantethine under hypoxic perfusion}

The sequential changes after application of pantethine $5 \times 10^{-3} \mathrm{Gm} / \mathrm{ml}$ under hypoxic perfusion are also summarized in Fig. 1. Parameters during the control period and hypoxic perfusion for $30 \mathrm{~min}$ did not change from those of hypoxic perfusion.

RMP and $d V / d t_{\max }$ did not change significantly with application of 
pantethine. Application of pantethine under hypoxic perfusion increased APA significantly to $96 \pm 3.4 \mathrm{mV}(\mathrm{p}<0.05)$ after 20 min (hypoxic perfusion for $50 \mathrm{~min}) . \mathrm{APD}_{20}$ was lengthened to $97 \pm 14.7 \quad(\mathrm{p}<0.05)$ and $87 \pm 13.5$ msec $(\mathrm{p}<0.05)$ after 20 and $30 \mathrm{~min}$, respectively. $\mathrm{APD}_{50}$ was lengthened to $150 \pm 9.2(\mathrm{p}<0.05), 153 \pm 12.2(\mathrm{p}<0.01)$ and $143 \pm 15.5 \mathrm{msec}(\mathrm{p}<0.05)$, after 10,20 and 30 min. $\mathrm{APD}_{90}$ was also lengthened to $191 \pm 9.3(\mathrm{p}<0.05), 197 \pm$ $12.4(\mathrm{p}<0.01)$ and $188 \pm 10.7 \mathrm{msec}(\mathrm{p}<0.01)$, after 10,20 and $30 \mathrm{~min}$. ERP was lengthened to $192 \pm 12.0 \mathrm{msec}(\mathrm{p}<0.05)$ after $30 \mathrm{~min}$.

Action potentials in a representative case are shown in Fig. 3. Application of pantethine under continued hypoxia partially restored the shortening of APD and ERP caused by hypoxic perfusion.

\section{Discussion}

Pantethine is known to be converted to GoA in the rat liver. CoA is an essential cofactor for many synthetic and catabolic reactions, but its primary importance in cardiac muscle is in energy production. Although the factors ${ }^{8-10}$ ) that regulate the biosynthesis of $\mathrm{CoA}$ are not clearly understood, the rate of CoA synthesis by the liver appears to be responsive to changes in pantothenic acid concentration under some conditions. ${ }^{11)}$ When various amounts of pantothenic acid or pantethine were added to a pantothenic acid deficient diet in the rat, the amounts of CoA were correspondingly increased in the liver. ${ }^{12)}$ It has also been suggested that the synthetic pathway from pantethine to CoA is shorter and more effective than from pantothenic acid to CoA. Activation of free fatty acids by CoA occurs in the cytosol, resulting in the formation of fatty acyl CoA esters ${ }^{13)}$ which can be used either for $\beta$ oxidation in the mitochondria or for triglyceride and phospholipid synthesis in the cytosol.

During the early phase of myocardial ischemia or hypoxia, ${ }^{14), 15)}$ it has been reported that levels of free CoA, ATP and creatine phosphate decline. Shibano and Abiko ${ }^{16}$ have reported that partial occlusion of the canine coronary artery reduced the endo- and epicardial ATP and creatine phosphate levels significantly and that the pantethine injection minimized the decrease in the ATP and creatine phosphate levels produced by partial occlusion. They concluded that pantethine increases myocardial $\mathrm{pH}$ that had been reduced by partial occlusion of the coronary artery, probably by lowering consumption of myocardial ATP and hence creatine phosphate.

Minami et $\mathrm{al}^{17)}$ have reported that a pantethine concentration of $5 \times$ $10^{-3} \mathrm{Gm} / \mathrm{ml}$ induced a significant increase in the isometric tension of the papillary muscles of guinea-pigs and the positive inotropic action of pantethine 
might be attributed to the increased biosynthesis of $\mathrm{CoA}$ in the myocardium.

In the present study, hypoxia caused appreciable changes in the transmembrane action potential of canine papillary muscle. RMP, APA and $\mathrm{dV} / \mathrm{d} t_{\max }$ were decreased and APD and ERP were shortened. The shortening of APD and ERP in this study was less than in previous reports, ${ }^{11,2)}$ as oxygen content of hypoxic perfusion $\left(\mathrm{pO}_{2} 60-65 \mathrm{mmHg}\right)$ was higher and thus hypoxia in this study was milder than that in previous reports. Application of pantethine under hypoxic perfusion prolonged APD and ERP significantly.

The shortening of the action potential during hypoxia has been attributed to an increase in potassium outward current ${ }^{18)}$ or a decrease in slow inward current. ${ }^{19}$ The decrease in slow inward current may be the consequence of a decrease in $\mathrm{g}_{c a}$ and/or a decrease in equilibrium potential for $\mathrm{Ca}^{2+}$ ions. On the other hand, the APD of the hypoxic guinea-pig was related to ATP generated by glycolysis ${ }^{4}$ and intracellular injection of ATP has been shown to elevate the plateau potential and prolong APD. ${ }^{201}$ A close relationship between ATP and slow inward current may be due to two mechanisms. First, a decrease in ATP, which is a strong chelator of $\mathrm{Ca}^{2+}$, would increase the concentration of free $\mathrm{Ca}^{2+}$ near the inner surface of the membrane, decreasing the driving force for $\mathrm{Ca}^{2+}$ ions. ${ }^{21)}$ Secondly, ATP might control gca directly via intracellular cyclic AMP. ${ }^{22)}$ An increase in potassium outward current caused by hypoxia may be mediated by a rise in intracellular $\mathrm{Ca}^{2+}$ activity. ${ }^{23)}$ Recently, an ATP-regulated $\mathrm{K}^{+}$channel24) has been shown in cardiac muscle by use of the patch-clamp technique. Therefore, it may be reasonable to speculate that prolongation of APD by pantethine during hypoxia is caused by an increase in intracellular ATP content through an increase in slow inward current or a decrease in potassium outward current.

A decrease in high energy phosphates such as ATP and creatine phosphate results in a depression of the active transport system and in an increase in the intracellular concentration of $\mathrm{Na}^{+}{ }^{25}$ An increase in the intracellular $\mathrm{Na}^{+}$content has been found to cause shortening of ADP. ${ }^{26)}$ Intracellular acidification might decrease slow inward current, ${ }^{27)}$ though the fall in intracellular $\mathrm{pH}$ in hypoxia is much less than in ischemia. ${ }^{28)}$ The mechanism of the effects of pantethine during hypoxia demands further investigation.

In this study, it was shown that external application of pantethine could protect and partially reverse the deterioration in action potential produced by hypoxic perfusion. These findings could be an explanation of the possible antiarrhythmic effects of pantethine. 


\section{REFERENCES}

1. Trautwein W, Gottstein U, Dudel J: Der Actionsstrom der Myokardfaser im Sauerstoffmangel. Pflügers Arch 260: 40, 1954

2. MacLeod DP, Daniel EE: Influence of glucose on the transmembrane action potential of anoxic papillary muscle. J Gen Physiol 48: 887, 1965

3. Webb JL, Hollander PB: Metabolic aspects of the relationship between the contractility and membrane potentials of the rat atrium. Girc Res 4: 618, 1956

4. McDonald TF, MacLeod DP: Metabolism and the electrical activity of anoxic ventricular muscle. J Physiol 229: 559,1973

5. Akashi A, Irie K, Kunisada S, Watanabe K, Tamura K: Effects of pantethine on experimental arrhythmia models. in 6th Pantethine Symposium, Asahi Medical Press, Tokyo, p 200, 1982

6. Levintow L, Novelli GD: The synthesis of coenzyme A from pantethine. Preparation and properties of pantethine kinase. J Biol Chem 207: 761, 1954

7. Rozanov AY, Sawluchinskaya LG, Zhdanovich ES, Kopelevich VM: Biosynthesis of acylation coenzyme from the pantothenate derivatives in the organism of white rats. Biokhimiya 35: 58,1970

8. Germinario RJ, Waller JR: Transport of pantothenic acid in Lactobacillus plantarum. Can J Microbiol 23: 922, 1977

9. Skrede S, Halvorsen O: Mitochondrial biosynthesis of coenzyme A. Biochem Biophys Res Commun 91: 1536, 1979

10. Robishaw JD, Berkich D, Neely JR: Rate-limiting step and control of coenzyme A synthesis in cardiac muscle. J Biol Chem 257: 10967, 1982

11. Reibel DK, Wyse BW, Berkich DA, Palko WM, Neely JR: Effects of diabetes and fasting on pantothenic acid metabolism in rats. Am J Physiol 240: E597, 1981

12. Nakamura $\mathrm{T}$, Kusunoki $\mathrm{T}$, Soyama $\mathrm{K}$ : Effect of pantothenic acid administration on 4'phosphopantethine and dephospho-CoA content in rat liver determined by the use of biosynthetic reaction of CoA in vitro from these precursor substances. J Vitaminol 13: 289, 1967

13. Tubbs PK, Garland PB: Variations in tissue contents of coenzyme $A$ thio esters and possible metabolic implications. Biochem J 93: 550, 1964

14. Whitmer JT, Idell-Wenger JA, Rovetto MJ, Neely JR: Control of fatty acid metabolism in ischemic and hypoxic hearts. J Biol Chem 253: 4305, 1978

15. Shug AL, Thomsen JH, Folts JD, Bittar N, Klein MI, Koke JR, Huth PJ: Changes in tissue levels of carnitine and other metabolites during myocardial ischemia and anoxia. Arch Biochem Biophys 187: 25, 1978

16. Shibano $\mathrm{T}$, Abiko $\mathrm{Y}$ : Effect of pantethine on myocardial $\mathrm{pH}$ reduced by partial occlusion of the coronary artery in dogs with special reference to the myocardial levels of adenosine triphosphate, creatine phosphate, and lactate. Arch Int Pharmacodyn 255: 281, 1982

17. Minami M, Yasuda H, Saito H: Positive inotropic and negative chronotropic effect of pantethine on isolated cardiac muscle of guinea-pigs. Experientia 39: 1028, 1983

18. Vleugels A, Vereecke J, Carmeliet E: Ionic currents during hypoxia in voltage-clamped cat ventricular muscle. Circ Res 47: 501, 1980

19. Payet MD, Scanne OF, Ruiz-Ceretti E, Demers JM: Slow inward and outward currents of rat ventricular fibers under anoxia. J Physiol (Paris) 74: 31, 1978

20. Taniguchi J, Noma A, Irisawa $\mathrm{H}$ : Modification of the cardiac action potential by intracellular injection of adenosine triphosphate and related substances in guinea pig single ventricular cells. Circ Res 53: 131, 1983

21. Hyde A, Cheneval JP, Blondcl B, Girardicr L: Electrophysiological corrclates of energy metabolism in cultured rat heart cells. J Physiol (Paris) 64: 269, 1972

22. Watanabe AM, Besch HR: Cyclic adenosine monophosphate modulation of slow calcium 
influx channels in guinea pig hearts. Circ Res 35: 316, 1974

23. Bassingthwaighte JB, Fry CH, Mcguigan JAS: Relationship between internal calcium and outward current in mammalian ventricular muscle. A mechanism for the control of the action potential duration? J Physiol 262: 15, 1976

24. Noma A: ATP-regulated $\mathrm{K}^{+}$channels in cardiac muscle. Nature 305: 147, 1983

25. Baumgarten CM, Cohen CJ, McDonald TF: Heterogeneity of intracellular potassium activity and membrane potential in hypoxic guinea pig ventricle. Circ Res 49: 1181, 1981

26. Niedergerke R, Orkand RK: The dependence of the action potential of the frog's heart on the external and intracellular sodium concentration. J Physiol 184: 312, 1966

27. Kohlhardt M, Haap K, Figulla HR: Influence of low extracellular pH upon the Ca inward current and isometric contractile force in mammalian ventricular myocardium. Pfïgers Arch 366: 31, 1976

28. Neely JR, Whitmer JT, Rovetto MJ : Effect of coronary blood flow on glycolytic flux and intracellular pH in isolated rat hearts. Circ Res 37: 733, 1975 